\title{
How does the ground reaction force affect the 6 second sprint performance?
}

\author{
Izzet KIRKAYA 1, Ilker YILMAZ², Baris GUROL ${ }^{2}$ \\ ${ }^{1}$ Graduate School of Health Sciences, Anadolu University, Department of Physical Education and Sports, Eskisehir, Turkey \\ 2 Faculty of Sport Sciences, Anadolu University, Eskisehir, Turkey \\ Address Correspondence to I. Kırkaya, e-mail: izzetkirkaya@windowslive.com
}

\begin{abstract}
The purpose of this study was to determine kinetics and kinematics of various 6 second sprinting load with \%0GRF, \%10GRF and \%15GRF. Different loads of GRF have been analysed for seeing effect of the increasing ground reaction force. 8 female sportswomen (age=24.7 \pm 6.2 year; body weight $=61.27 \pm 8.79 \mathrm{~kg}$; height $=172.4 \pm 11.37 \mathrm{~m}$ ) of Anadolu University Youth and Sport Club that competes in the second division of Turkey Women's Basketball participated in this study. 6s. sprint kinematical analysis of the participants was made with two fast filming cameras (A602f, Basler, Germany) that are able to record up to $500 \mathrm{~Hz}$ and a software program (SIMI 7.3, Germany) that is able to record the scenes simultaneously into computer in $60 \mathrm{~Hz}$. The sprints that is with \%0, \%10 and \%15 loads were applied on non-motorised treadmills during $6 \mathrm{~s} .$, it was recorded with avi. format and the scenes which are in equal length and simultaneous were analysed. The difference among three different measurements $(0 \%, 10 \%, 15 \%$ ground reaction force) that belongs to one group was tested with One Way Anova after homogeneity of variances and significance level was taken as $p<0.05$. In the 6second sprint tests that were done with $\% 0, \% 10, \% 15$ ground reaction force, a statistically, on highest degree significant result was found among the distance that was passed, average velocity, average horizontal force, the top velocity and the top horizontal force ( $\mathrm{p} \leq 0.01)$. A statistically significant relationship was not found between average vertical force and vertical force on the peak velocity ( $p>0.05)$. In the 6second sprint tests which was done with $0 \%, 10 \%, 15 \%$ GRF of knee and elbow joints, statistically significant relation was not able to be found among angle, angular velocity, vertical velocity, horizontal velocity and resultant velocity $(p>0.05)$. Based on Bonferroni correction post test results there were statistically significant differences have been found between ground reaction forces (GRF0 - GRF10; $<<0.05$ \& GRF0 - GRF15; $\mathrm{p}<0.001$ ) and there were no statistically significant differences have been found between ground reaction forces $(\mathrm{p}>0.05)$. During the 6 second sprints that were done with $0 \%, 10 \%, 15 \%$ of the participants' body weights, it has been seen that vertical ground reaction force did not increase. This also shows that the participants could apply more force to the ground to accelerate and accordingly they carried out the sprint performance in a longer time. Not to be found a significant relationship among angle, angular velocity, horizontal velocity, vertical velocity and resultant velocity arises from reacting to ground reaction force in the same way with the sprint that is done with body weight. The participants could not increase their velocity in the face of increasing ground reaction force and therefore realized the 6second sprint performance in a longer time. Consequently, it has been deduced that they could not adapt acutely to ground reaction force and change their sprint styles to accelerate. To overcome the braking components of ground reaction force, supramaximal and plyometric types of trainings can be suggested.
\end{abstract}

Keywords: Ground reaction force, motion analysis, sprint biomechanics.

\section{INTRODUCTION}

In most sports branches sprint run is a component that has critical importance to reach success. Sprint running composes of start, acceleration, maximal speed, deceleration and finish steps. Acceleration phase depends on the first acceleration phase that contains differences in step length seen between $0-10 \mathrm{~m}$ (12), continuous acceleration phase contains reaching to maximal speed from $11 \mathrm{~m}$, high incidence of reaction time and the production of power in the time of leaping forward (13).
There is a linear relation between force and sprint performance. The sprinters who has greater force present greater performance in contrast with the others. This indicates that the reaction force coming from the ground and forming driving force during run have a great role on deciding on sprint performance (2). During movement the reaction that forms towards to the force that athlete transfers to the ground is named ground reaction force (GRF). Reaction forming towards each effect that is occurred for movement is created and met by skeleton and muscle system. Within this context 
faction and reaction force that occurred in muscle and skeleton system for medical and sportive purpose is supposed to be measured scientifically (6). In order to measure this reaction force that occurred on both horizontal and vertical axis and to get force outcome, specifically improved equipment is needed. Vertical and horizontal forces that occur during running are tested in lab environment by non- motorized treadmills. With this equipment an analysis of run performance can be made real- like in lab environment. With these analyses, some criteria that affect the performance directly such as presented maximal force, maximal power, maximal running speed, maximal heart rate and maximal oxygen consumption can be measured as well (4).

Ground reaction forces that appear at the same time the voluntary participator stars to running composed of horizontal and vertical forces components. While the participators who are tied to a point from their waists are circling the nonmotorized treadmills based on their own pace, horizontal force appears and this is measured by strain gauge mechanism that the participators tied to from their waists. The vertical force is measured by pressure gauge, piezo, in force platform placed under the treadmills (11). Hence, it will become observable both kinetically and kinematically that the part which Luhtanen \& Komi (7) categorized the first step of sprint as propulsion and braking. As well as these two components compose total contact time together.

With the developments in biomechanics field, contact flight parts have changed. In order to accelerate more touching the ground is supposed to be decreased as much as possible and the time spending on the air should be increased. During sprint these steps can show some changes such as more acceleration or extended of braking time paralleled with the force that body weight, leg length or m.gluteus maximus, m.vastus lateralis, m.rectus femoris or m.gastrocnemius form in the course of touching the ground (1).

In this study it is aimed that it can be observable, in 6 sn sprint which will be performed in different ground reaction forces, that how much the sprint technique changes and the situations we meet when the short term supramaximal sprint is assigned as workout by comparing natural sprint parameters and short supramaximal run.

\section{MATERIALS \& METHOD}

\section{Participants}

In the research 8 female athletes from Anadolu University Youth and Sports Club in the 2. League of Turkey Women Basketball took place (age = $24.7 \pm 6.2$ year; body weight $=61.27 \pm 8.79 \mathrm{~kg}$; height $=$ $172.4 \pm 11.37 \mathrm{~m})$.

This study was approved by the local ethics committee. All subjects signed informed consent forms before enrolment. The subjects volunteered to participate in 4 testing visits separated by 24 hours. Visit 1 was a familiarization.

\section{Procedures}

The horizontal and vertical ground force the volunteer participators will present during the sprint was measured by 4 force platforms under the belt sized $55 \mathrm{~cm} \times 173 \mathrm{~cm}$ to measure the vertical forces and also to measure the horizontal forces nonmotorized treadmills that have power transformer tied at the waist and goniometer were used (Woodway Force 3.0 Woodway Inc, Waukesha, USA).

Kinematical analyses of 6second sprint of the volunteers participators were made with two cameras (A602f, Basler, Germany) that can make fast shooting and record up to $500 \mathrm{~Hz}$ and also a software program (SIMI 7.3, Germany) that can record the scene in $60 \mathrm{~Hz}$ simultaneously on the computer was used (Griffiths, 2006). The cameras were placed 4 meter distance to the non-motorized treadmills and the place of them was not changed until the tests were finished. For calibration, 12 points were determined on the cameras in advance and calibration cage with sizes $1.00 \mathrm{~m} \sim 2.50 \mathrm{~m} \sim 1.00 \mathrm{~m}$ was used. \%0 load, \%10 load and \%15 load sprints were applied on non- motorized treadmill during 6 Sc and it was recorded avi format. Then the simultaneous scenes were analyzed.

\section{Marking}

On volunteer participators' bodies, on their right wrists "ulnar styloid protrusion", on their right elbow "humerus lateral epikondil", on their right shoulder "acromiyoclavikular joint", on their right ankle "lateral malleol", on their right knee "lateral femoral kondil" and on their right hip "bilateral greater trochanter" are the joints that are chosen for the markers. To prevent some marking faults and breaks, all the raw data obtained were filtered with 
low pass filter, Butterworth that has $6 \mathrm{~Hz}$ filtration frequency (16).

\section{Protocol of the test}

On the other exercise bouts volunteers perform maximal sprints that last 6second with their own body weight, with extra \%10 GRF (subjects'own body weight $+\% 10 \mathrm{GRF}$ ) of their body weight and extra \%15GRF (subjects'own body weight + $\% 15 G R F)$. Every test day, they practiced 4 sprints in total and the best one was recorded (12). GRF that appeared during the sprint were transferred to digital platform with $200 \mathrm{~Hz}$ data collection speed. Kinetic and Kinematical analyses were made with Simi Motion Analyze System (Reality Motion Systems GmbH-Ger) and three cameras with high speed that can record in $500 \mathrm{~Hz}$. (1).

\section{Analysis}

Whether the data ranges normally or not is controlled by Kolmogorov- Smirnov test. The data that has normal range was tested with using One Way ANOVA and Bonferroni Correction post -

test in order to find the differences between GRF and kinetic and kinematical parameters and then the level of significance was determined as 0.05 .

\section{RESULTS}

In the Figure 1, depending on increasing ground reaction force, it is seen that the distance that is been passed decreases. Based on Bonferroni correction post test results there were statistically significant differences have been found between ground reaction forces (GRF0 - GRF10; $<<0.05 \&$ GRF0 - GRF15; $\mathrm{p}<0.001)$.

In the Figure 2 depending on increasing ground reaction force, during 6second sprint performance it is seen that peak speed values decreases linearly. Based on Bonferroni correction post test results there were statistically significant difference have been found between ground reaction forces (GRF0 GRF15; $\mathrm{p}<0.01)$.

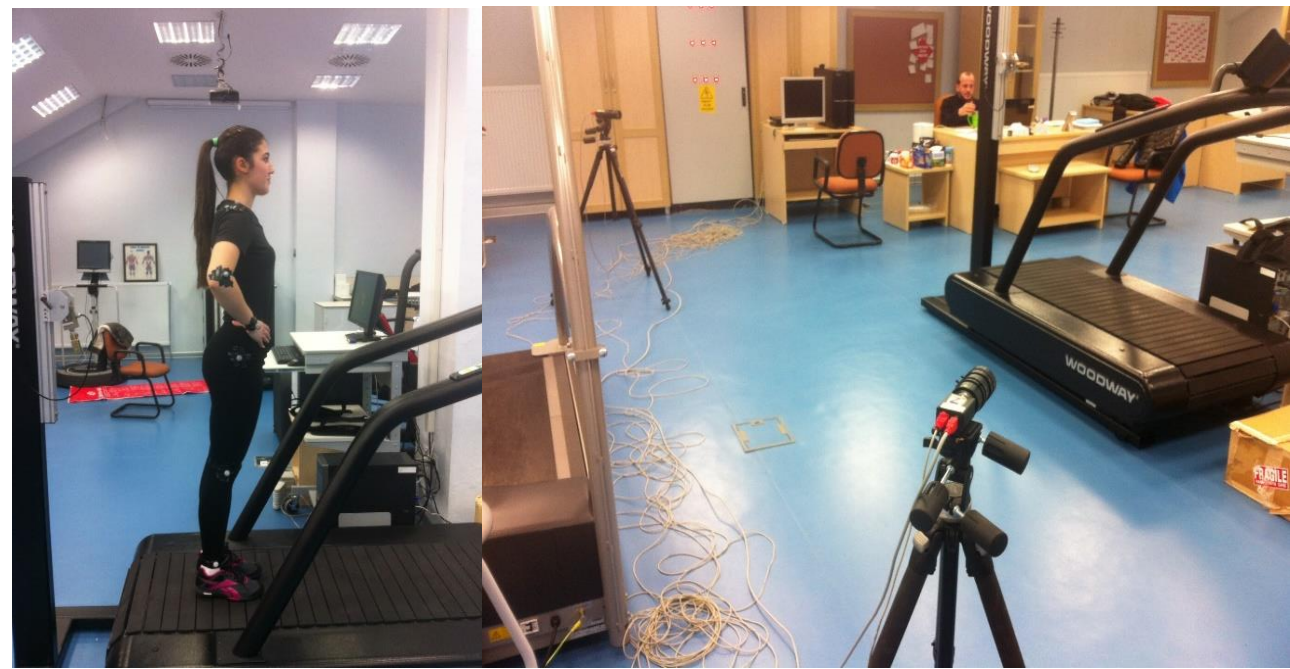

Picture 1. Marker and Camera Replacement

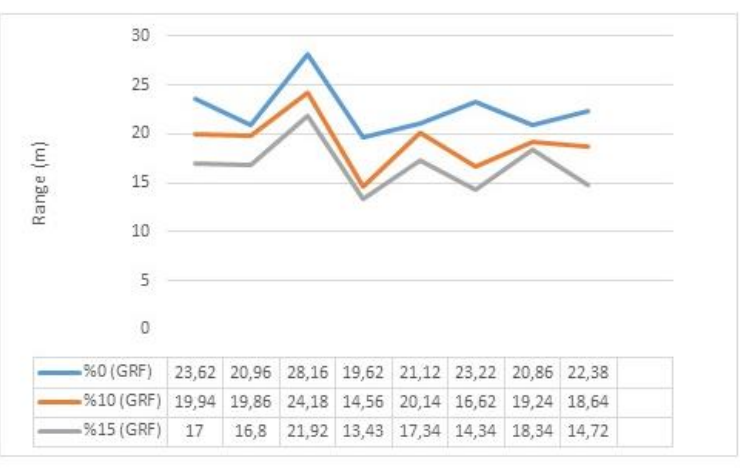

Figure 1. Milage to the degree of ground reaction force.

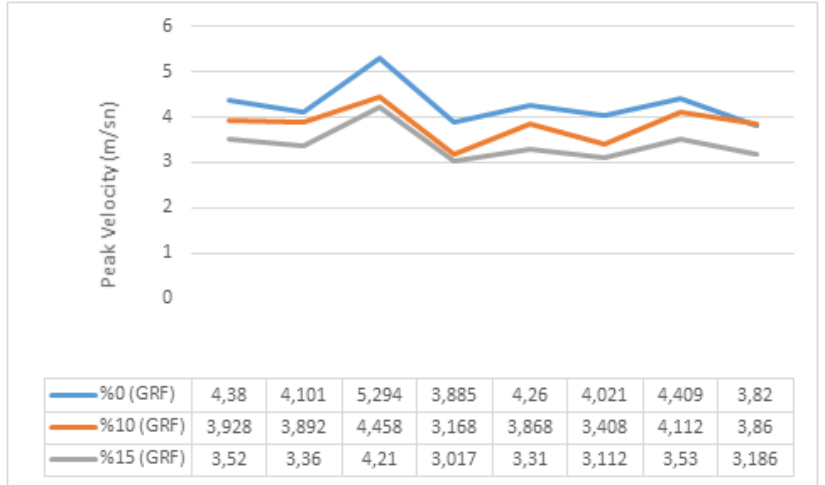

Figure 2. Peak speed to the degree of ground reaction force. 


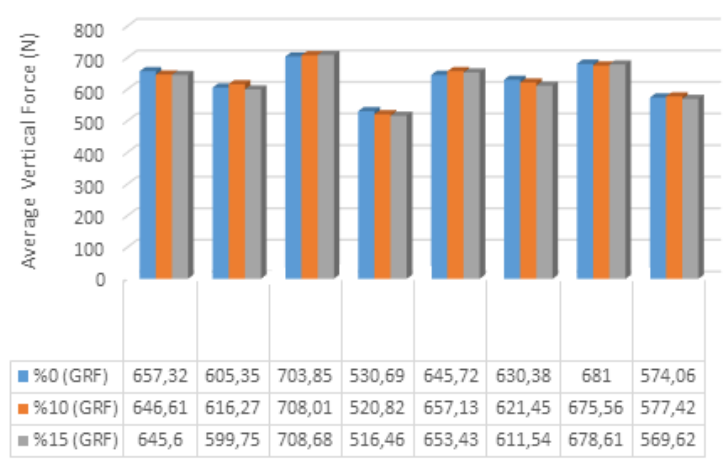

Figure 3. Average vertical force to the degree of ground reaction force.

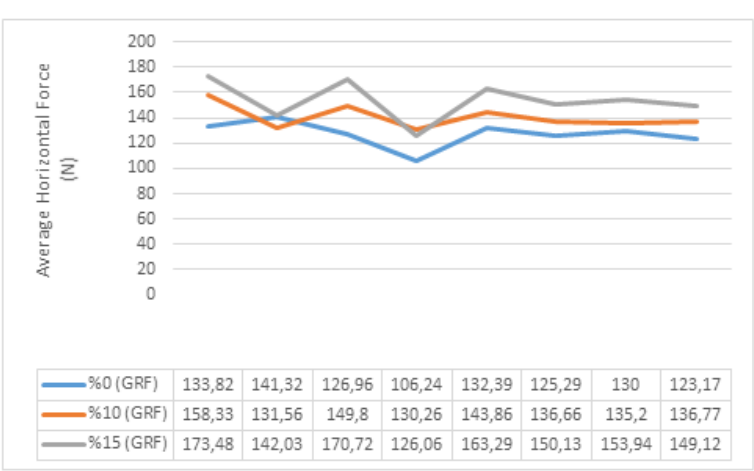

Figure 4. Average horizontal force to the degree of ground reaction force.

Table 1. Elbow joint movement analysis

\begin{tabular}{lcccccccc}
\hline GRF & Angle & Angular Velocity & Vx & Vy & Vresultant & Ax & Ay & Aresultant \\
\hline$\% 0$ & 102,85 & 217,78 & 1,84 & 1,87 & 3,12 & 9,72 & 22,92 & 15,80 \\
$\% 10$ & 86,75 & 257,58 & 1,81 & 1,63 & 3,00 & 18,82 & 16,17 & 23,51 \\
$\% 15$ & 96,58 & 294,35 & 1,64 & 1,08 & 2,59 & 13,23 & 11,43 & 14,30 \\
\hline
\end{tabular}

Table 2. Knee joint movement analysis

\begin{tabular}{lcccccccc}
\hline GRF & Angle & Angular Velocity & Vx & Vy & Vresultant & Ax & Ay & Aresultant \\
\hline$\% 0$ & 112.68 & 484.51 & 2.39 & 1.87 & 3.36 & 8.76 & 15.15 & 13.10 \\
$\% 10$ & 126.74 & 328.73 & 2.11 & 1.17 & 2.65 & 15.65 & 7.61 & 13.59 \\
$\% 15$ & \multirow{2}{*}{119.84} & 409.53 & 1.79 & 1.07 & 2.26 & 19.33 & 7.97 & 13.10 \\
\hline
\end{tabular}

In the values of vertical force that is applied depending on increasing ground force, there are no statistically significant differences were found. Based on Bonferroni correction post test results there were no statistically significant differences have been found between ground reaction forces ( $p>0.05)$.

When ground reaction force increases, horizontal component of ground reaction force increases as well. Based on bonferroni correction post test results there were statistically significant difference have been found between ground reaction forces (GRF0 - GRF15; $\mathrm{p}<0.01$ ).

When we analyse the Table 1, on the instant of 6 second. Sprint performance we can see that athletes' elbow joint movement differences on nonmotorized treadmill \%0, \%10 and \%15 ground reaction force. When the load of treadmill increases elbow angular speed increases as well, vertical speed $(\mathrm{Vy})$, horizontal speed $(\mathrm{Vx})$, resultant speed (Vres) and vertical acceleration (Ay) decrease. Based on bonferroni correction post test results there were no statistically significant differences have been found among ground reaction forces and elbow joint variables $(p>0.05)$.
When we analyse Table 2, on the instant of 6 sc. Sprint performance we can see that athletes' knee joint movement differences on non-motorized treadmill $\% 0, \% 10$ and $\% 15$ ground reaction force. When the load of treadmill increases vertical speed $(\mathrm{Vy})$, horizontal speed (Vx), resultant speed (Vres) decrease horizontal acceleration (Ax) increases. Based on bonferroni correction post test results there were no statistically significant differences have been found among ground reaction forces and knee joint variables $(p>0.05)$.

\section{DISCUSSION}

When all of the tables are examined, it is possible to say these; (a) because of the increasing GRF, milage decreased, (b) individuals' peak speed decreased, (c) the changes of vertical force values are minimal and statistically meaningless, (d) bracing effect of horizontal force components of GRF increased, (e) there is no statistically significant difference between elbow and knee movement analyses.

Based on increasing ground reaction force volunteer participators' vertical forces stayed stable. This is also a signal of not being able to adapt the 
changing conditions. In the studies of Mero and Komi (9) and Mero et al. (10), for maximum force, it was seen that they decrease braking GRF to minimum and increase impulsive GRF to maximum. However in our study, while the vertical force component of GRF stayed almost stable, horizontal force component increased. In our study, because of that propulsive component of vertical ground reaction time does not increase, while the force that is applied to the ground stays stable, horizontal braking force increases. Therefore, the athletes could not increase their own speed in horizontal axis. When ground reaction force increases, depending on that vertical ground reaction force is supposed to both increase and occur in shorter time. However in every GRF values, vertical shows parallelism with the sprint that the participants performed with their own body weight.This situation was seen in every participator. Consequently against the increasing GRF they could not present the performance that they displayed against \% 0 GRF. As indicated in Weyand et al. (14)'s study, it is an advantage to obtain average GRF in the phase of acceleration and to touch the ground just for a short time.

Because of the fact that a sprinter is supposed to touch to the ground in a very effective way in order to decrease braking GRF and increase impulsive GRF, before touching to the ground, forward lateral speed of the foot should decrease. So as to apply this, in the time of touching to the ground, the sprinter is supposed to reach high extension speed in hip joint and high flexion speed in knee joint. To increase impulsive GRF, in the phase of leg swing it is needed to increase hip and knee joint to high angular speed (5). As a result of Hunter et al. (5)' study for optimal acceleration in accordance with these results that they mention about, in our study it has seen that when GRF increases, it moves away from mentioned optimal acceleration. The angular speeds of knee joint decreased in direct proportion to increasing GRF. In consequence of this maximal speed decreased.

Heymen (3) determined that the main condition which is a need for reaching to maximal sprint speeds is to decrease the touch to the ground as much as possible. The reason of this in stand phase there is little lateral distance between elite sprinters' bodies' gravity center and their support feet in the front. Also he said that with this strategy in the phase of stand the sprinter is able to decrease the touch to the ground and so decrease the effects of reaction forces that can come from the ground to minimum. When the Table 2 is examined, it is seen that the highest speed is reached under the effect of the lowest GRF. Heymen's comment is compatible with Young's (17) and Weimann \& Günter's (15) claim. How fast the leg swing towards the back is, it has little touch to the ground as well. Landing on the ground of the leg quickly will decrease resisting duration against horizontal and vertical forces coming from the ground and so with bracing forces touching to the ground will lose its effect.

Morin et al. (11) found the average vertical force as $723 \pm 59 \mathrm{~N}$ in the sprint studies that they applied during 6second and said these values are close the participators' body weight $(726 \pm 54 \mathrm{~N})$. Our study has parallels with this situation. However decrease was observed in acceleration due to effect of lateral braking of GRF and not transferring more force to the ground. Continually decrease of average horizontal force against increasing GRF loads is an example of not being able to transfer force to the ground.

As a result; in this study that include Cross section research model, we observed the participators' 6second sprint performances against increasing GRF. In order to evaluate participators' chronical adaptation to this condition, this research method that include supramaximal feature should be applied in the term of block work out or mezocycle work out. Furthermore to increase the speed of run, hip muscles flexion has a very important role (8). In the work out terms the practices that are combined with approaches which increase hip flexion speed may variously react to increasing GRF. In the future the chronical effects of such work outs can be researched. As a consequence, horizontal and vertical forces that form during the sprint appear because of braking effect of GRF and has negative effects on the athlete's acceleration. To accelerate anterior- posterior axis, horizontal and vertical components of GRF should be minimize as much as possible and impulsive forces should be tried to be increased. This can solely be possible with a high speed and effective touch.

\section{REFERENCES}

1. Ciacci S, Di Michele R, Merni F. Kinematic analysis of the braking and propulsion phases during the support time in sprint running. Gait \& Posture, 2010; 31(2), 209-212.

2. Comfort P, Bullock N, Stephen S. A comparison of maximal squat strength and 5-10 and 20 meter sprint times in athletes and recreationally trained men. Journal of Strength and Conditioning Research, 2012; 26(4): 937-940. 
3. Heymen M. Hamstring Injuries in Sprinting.2000; IAAF/NSA 3.01 .

4. Highton JM, Lamb KL, Twist C, Nicholas C. The reliability and validity of short-distance sprint performance assessed on a non-motorized treadmill. Journal of Strength and Conditioning Research, 2012; 26(2): 458-465.

5. Hunter JP, Marshall RN, McNair, PJ, Relationships between ground reaction force impulse and kinematics of sprintrunning acceleration. Journal of Applied Biomechanics, 2005; 21(1), 31-43.

6. Korkusuz F, Tümer T, Ortopedide Biyomekanik Yaklaşımlar, Ankara Üniversitesi Dikimevi Sağlık Hizmetleri Meslek Yüksekokulu Yıllığı 2001; Cilt 2 Sayı 1.

7. Luhtanen P, Komi PV. Force, power and elasticity-velocity relationship in walking, running and jumping. European Journal of Applied Physiology, 1980; 44 (3), 279-289.

8. Mann RA, Moran GT, Dougherty SE. Comparitive electromyography of the lower extremity in jogging, running and sprinting. The American Journal of Sports Medicine, 1986; 14(6): 501-510.

9. Mero A, Komi PV. Force-emg and elasticity-velocity relationships at submaximal, maximal and supramaximal running speeds in sprinters. European Journal of Applied Physiology, 1986; 55: 553-561.
10. Mero A, Komi PV, Gregor RJ. Biomechanics of sprint running. Sports Medicine, 1992; 13(6): 376- 393.

11. Morin BJ, Samozino P, Bonnefoy R, Edouard PBA. Direct measurement of power during one single sprint on treadmill. Journal of Biomechanics, 2010; (43): 1970-1975.

12. Murphy AJ, Lockie RG, Coutts AJ. Kinematic determinants of early acceleration in field sport athletes. Journal of Sports Science and Medicine, 2003; 2(4): 144-150.

13. Ross MD, Ratamess NA, Hoffman JR, Faigenbaum AD, Kang JC. Test effects of treadmill sprint training and resistance training on maximal running velocity and power. Journal of Strength and Conditioning Research, 2009; 23(2): 385-394.

14. Weyand P, Sternlight D, Bellizzi MJ, Wright S. Faster top running speeds are achieved with greater ground forces not more rapid leg movements. Journal of Applied Physiology, 2000; 89(5):1991-1999.

15. Wiemann K, Günter T. Relative activity of hip and knee extensors in sprinting - implications for training, New Studies in Athletics, 1995; Vol. 10, 29-49.

16. Winter DA. Biomechanics and motor control of movement. 1990; New York: Wiley.

17. Young M. Maximal velocity sprint mechanics, Human Performance Consulting, 2005. 